\section{ENGEVISTA}

Página da revista: http://www.uff.br/engevista/seer/

\title{
Produção e caracterização de membranas poliméricas, usando os aditivos cloreto de potássio e de lítio, em condições idênticas
}

\author{
Flávia Fernanda Mayumi Susuki ${ }^{1}$ \\ Paulo Roberto Paraíso ${ }^{2}$ \\ Paulo Henrique Souza Almeida ${ }^{3}$ \\ Akira Ito $^{4}$ \\ Rosângela Bergamasco ${ }^{5}$
}

\begin{abstract}
Resumo: Neste trabalho, foi investigado a produção de membranas poliméricas porosas assimétricas planas de 8 e 10\% Fluoreto de Polivinilideno (PVDF), 1\% de Polimetacrilato de Metila (PMMA), $1 \%$ de diferentes aditivos ( $\mathrm{sal} \mathrm{KCl}$ ou $\mathrm{LiCl}$ ) e como solvente, o N-N-Dimetilformamida. Para isso, um sistema automatizado e a técnica de Inversão de Fases foram utilizados para a síntese das membranas e estas foram caracterizadas quanto ao grau de retenção das proteínas globulares BSA e $\Upsilon$-Globulina, estimativa do raio médio de poros, fluxo de água de osmose inversa e de soluções de $100 \mathrm{mg} / \mathrm{L}$ das respectivas proteínas globulares. Os resultados da respectiva caracterização mostraram que as membranas sintetizadas com $\mathrm{LiCl}$, em relação às sintetizadas com $\mathrm{KCl}$, tiveram maior retenção de proteínas globulares e espessura, raio médio de poros e fluxos de permeado aquoso menores. Assim, é possível averiguar que as membranas de mesma concentração polimérica produzidas com LiCl, nas mesmas condições físicas e operacionais, são mais eficientes.
\end{abstract}

Palavras-chave: Membrana polimérica, produção, caracterização, aditivo.

\footnotetext{
${ }^{1}$ UEM - Universidade Estadual de Maringá

${ }^{2}$ UEM - Universidade Estadual de Maringá

${ }^{3}$ UFMT - Universidade Federal do Mato Grosso

${ }^{4}$ TOKODAI - Tokyo Institute of Technology

${ }^{5}$ UEM - Universidade Estadual de Maringá
} 
ISSN: $1415-7314$

ISSN online: 2317-6717

Abstract: In this study, was investigated the production of of flat asymmetric porous polymer membranes constituent of 8 e 10\% Polyvinylidene Fluoride (PVDF), 1\% Polymethyl Methacrylate (PMMA), 1\% of different additives (salt $\mathrm{KCl}$ or $\mathrm{LiCl}$ ) and as solvent, $\mathrm{NN}$-dimethylformamide. For this, an automated system and the Phase Inversion technique were used in order to produce the membranes which were characterized regarding the retention degree of BSA and $\Upsilon$-Globulin globular proteins, estimate of the average pore radius, water flow of reverse osmosis and of $100 \mathrm{mg} / \mathrm{L}$ solutions of these globular proteins. The results of their characterization showed that the membranes produced with $\mathrm{LiCl}$ in relation to the synthesized $\mathrm{KCl}$, have greater retention of globular proteins and thickness, and average pore radius and flow aqueous permeate smaller. Thus, it is possible to verify that the membranes of the same polymeric concentration produced with $\mathrm{LiCl}$, at the same physical and operating conditions, are more efficient.

Keywords: Polymeric membrane, production, characterization, additive. 


\section{Introdução}

Membrana sintética é uma estrutura que restringe, totalmente ou parcialmente, o transporte de uma ou várias espécies químicas presentes em uma mistura.

Os processos de separação com membranas (PSM) podem ser aplicado industrialmente com inúmeras vantagens, entre elas, a operação contínua com baixo consumo energético e a facilidade de ser combinado com outros processos de separação (Polleto et al., 2012). Por isso, membranas estão sendo utilizadas amplamente, em novos e diferentes processos de separação, bem como em substituição aos processos já existentes e nas tecnologias de purificação (Kocherginsky et al., 2007). Dessa forma, por sua versatilidade, as membranas estão sendo amplamente utilizadas nas indústrias de alimentos, químicas, farmacêuticas, têxteis (Branzinha \& Crespo, 2010), tratamento de água e efluente (Balannec et al., 2005; Baldasso et al., 2011).

Nesse sentido, o campo da síntese de membranas tem sido relevante no desenvolvimento de novos materiais poliméricos com diferentes estruturas. O objetivo desse desenvolvimento é gerar o aumento do fluxo de permeado e retenção de compostos a pressões reduzidas. Além disso, as membranas devem ter durabilidade e alto grau de seletividade. Segundo Habert et al. (2006), um campo importante da síntese de membranas é a produção de membranas poliméricas microporosas que podem ser obtidas por diferentes métodos, tais como: inversão de fase, sinterização, estiramento ou gravação.

A técnica de inversão de fases é a mais utilizada para obtenção de membranas microporosas simétricas e assimétricas (Young et al., 2002), sendo amplamente utilizada no preparo de membranas comercias com diferentes tipos de morfologia e propriedades de transporte (Loeb \& Sourirajam, 1962). De forma sintética, a produção de membranas pela técnica de inversão de fases por imersãoprecipitação, compreende das seguintes etapas: homogeneização dos componentes, desareação da solução, espalhamento da solução homogeneizada sobre um suporte, aplicação da imersãoprecipitação e secagem.

Neste trabalho, foi utilizada essa técnica para a síntese de membranas poliméricas porosas assimétricas. Segundo Rahimpour et al., 2009, a respectiva técnica de inversão de fases por imersãoprecipitação compreende na imersão do filme polimérico em um banho de precipitação (Figura 1) constituído de um não solvente, ou uma mistura solvente/não solvente, miscíveis em todas as proporções. Dessa maneira, ocorre a desestabilização termodinâmica da mesma solução, desencadeando-se a sua precipitação. Essa desestabilização da solução polimérica, segundo Leite $e t$ al. (2009), é fundamental para a formação da membrana porosa. Conforme o esquema da Figura 1 é possível observar a transferência de massa entre a solução polimérica e o banho de precipitação (difusão e a contradifusão do solvente). Desse modo, o mecanismo da transferência de massa no processo de síntese é fator determinante na morfologia das membranas. 


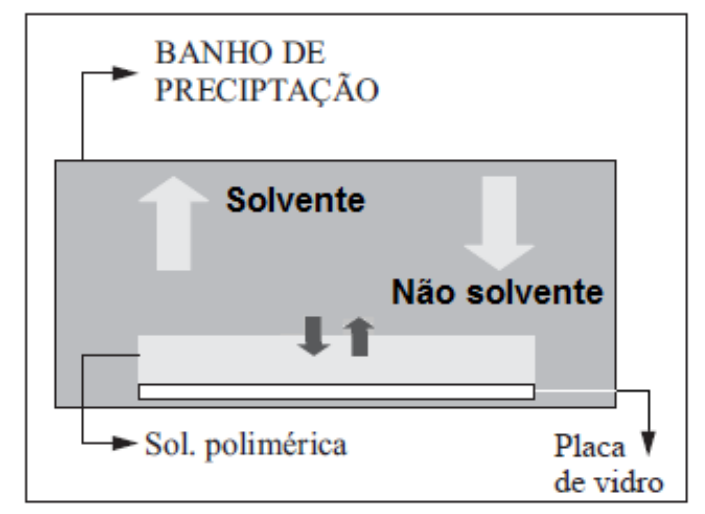

Figura 1 - Representação da técnica de inversão de fases por precipitação por imersão Fonte: adaptado de Carvalho et al., (2001)

Na literatura referente à síntese de membranas, observa-se que a concentração de polímeros tem influência significativa no tamanho dos poros e no custo das membranas.

Após a síntese, as membranas devem ser caracterizadas. Normalmente a caracterização pode ser realizada por vários parâmetros. Baker (2012) sugere que as membranas porosas podem ser caracterizadas quanto à distribuição de tamanho de poros, porosidade superficial e espessura.

Outro aspecto a ser observado na produção de membrana é a forma como ocorre o fluxo de material através da membrana. Segundo Baker (2012), o fluxo pode ser influenciado por fenômenos inerentes ao processo com membranas, tais como, polarização de concentração, formação de uma camada como um depósito e fouling.

Ribeiro et al. (2002) sintetizaram membranas de fluoreto de polivinilideno (PVDF) e de polisulfona (PSF), ambas com 13 e 18\% de cada polímero, empregando o $\mathrm{KCl}$ como aditivo e utilizando a técnica de inversão de fases, a fim de avaliar a remoção de cor e turbidez do efluente da indústria têxtil. Outro trabalho elaborado por Ribeiro et al. (2004) apresentou outras membranas de PVDF e de PSF de diferentes concentrações (12 e 17\%), com o mesmo aditivo e técnica, para a potabilização da água contaminada com a bactéria E. coli. Idris \& Ahmed (2007) produziram membranas, com $20 \%$ de polietersulfona (PES), empregando a respectiva técnica, utilizando o $\mathrm{LiCl}$ como aditivo.

O emprego do $\mathrm{KCl}$ e $\mathrm{LiCl}$ tem como objetivo tornar a membrana porosa. Por sua vez, a distribuição de poros na membrana depende de uma eficiente operação de homogeneização do sal na solução polimérica. Porém, observa-se que não existem trabalhos que apresentam a homogeneização detalhada da mistura polimérica de forma que apresentem um monitoramento rigoroso da homogeneização. Nesse sentido, o presente trabalho apresenta um sistema automatizado para o controle e monitoramento da temperatura durante todo o processo da homogeneização.

Assim, com o sistema automatizado para o controle da temperatura na homogeneização foi possível produzir membranas porosas assimétricas de raio médio de poros menor, com o emprego dos sais $\mathrm{KCl}$ e $\mathrm{LiCl}$, mais seletivas. 


\section{Metodologia}

As membranas foram produzidas no Departamento de Tecnologia da Universidade Estadual de Maringá (UEM) - Brasil e caracterizadas no Departamento de Engenharia Química de Tokyo Institute of Technology (TOKODAI) - Japão.

Os parâmetros utilizados na caracterização das membranas foram os seguintes: tensão de molhabilidade, ângulo de contato, grau de retenção de proteínas globulares (Albumina de Soro Bovino - BSA e Y-Globulina Bovina), raio médio estimado dos poros, espessura e fluxo de permeado (água de osmose inversa, soluções de $100 \mathrm{mg} / \mathrm{L}$ de BSA e de $\Upsilon$-Globulina, individualmente).

\subsection{Síntese das membranas}

Sintetizou-se membranas utilizando semelhantemente o procedimento de Susuki (2012), de mesmo material polimérico na proporção de 8 e 10\% de Polifluoreto de Vinilideno (PVDF) com 1\% do polímero Polimetacrilato de Metila (PMMA). Os reagentes da marca ALDRICH, com seu grau de pureza elevado, foram utilizados como recebidos para que as concentrações adotadas fossem mais exatas possíveis.

O PVDF e o PMMA, juntamente com $1 \%$ do sal $\mathrm{KCl}$ ou com o sal $\mathrm{LiCl}$, foram dissolvidos no solvente N-N-Dimetilformamida, utilizando-se um sistema automático de controle de temperatura (Figura 2).

O respectivo sistema desenvolvido no laboratório da UEM é composto por um frasco de vidro fechado com a solução polimérica a ser homogeneizada a uma temperatura máxima e praticamente constante de $40^{\circ} \mathrm{C}$ (1). Esse valor de temperatura foi controlado por meio do termopar (2) do agitador magnético ALLCROM (com prato aquecedor e controlador de temperatura) - modelo MS 400 (3), inserido na água de um recipiente (4). O monitoramento da temperatura foi realizado por meio do registro de dados da mesma, os quais foram obtidos a cada 30 segundos, pelo termopar (5) do equipamento Science Workshop 750 Interface (6) que registrava os dados de temperatura no computador por meio do programa DataStudio (7). Por fim, para impedir a variação dos dados, o conjunto formado pelos componentes (1), (2), (3), (4) e (5) encontrava-se no interior de uma cúpula de vidro (8).

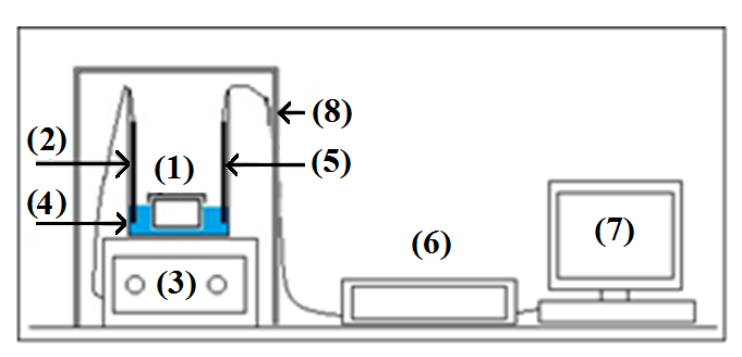

Figura 2. Esquema do sistema automático 
Dessa forma, obteve-se soluções poliméricas precursoras das membranas M1 e M3 (com o $\mathrm{KCl}$ ), bem como M2 e M4 (com o LiCl).

Após a completa homogeneização das respectivas soluções poliméricas, estas ficaram em repouso por $48 \mathrm{~h}$ no escuro e foram espalhadas, com auxílio de uma placa de vidro, sobre um suporte plano de poliéster-polipropileno fixado com fios de nylon de $0,35 \mathrm{~mm}$ de espessura. Posteriormente, o conjunto foi imerso em um não solvente (água destilada) à temperatura ambiente $\left(25^{\circ} \mathrm{C}\right)$ e seca à mesma temperatura, protegidas da luminosidade. Posteriormente, as membranas foram acondicionadas em embalagens plásticas individuais, sendo envolvidas preliminarmente por papel-toalha a fim melhorar a sua proteção.

\subsection{Caracterização das membranas produzidas}

A caracterização das membranas produzidas foi realizada em Tokyo Institute of Technology, para a avaliação do seu desempenho quanto à tensão de molhabilidade e ângulo de contato, grau de retenção de soluto, estimativa do raio médio dos poros, espessura, permeabilidade da água e de soluções aquosas.

\subsubsection{Teste de tensão de molhabilidade e ângulo de contato}

A tensão de molhabilidade e o ângulo de contato ilustram a facilidade com que uma superfície tem de realizar ligações de hidrogênio (ELZBIECIAK et al., 2008). Utilizou-se o teste de tensão de molhabilidade e do ângulo de contato a fim de caracterizar as superfícies das membranas quanto ao aspecto hidrofílico/hidrofóbico, de acordo com o procedimento ISO 8296 (ISO 8296, 2003) e Yuan \& Lee (2013), respectivamente.

Neste trabalho, o teste de tensão de molhabilidade baseou-se na observação do comportamento da gota de soluções comerciais denominadas Wetting Tension Test Mixture adquiridas da empresa Wako Pure Chemical Industries Ltd. A tensão superficial das soluções foi de 22,6; 30,0; 44,0; 50,0; 54,$0 ; 58,0 ; 60,0 ; 64,0 ; 70,0$ e 73,0 $\mathrm{mN} \cdot \mathrm{m}^{-1}$. Dessa forma, quando a gota de uma determinada solução comercial não se desfez após alguns segundos, repetiu-se o teste com solução de tensão maior. Quando o líquido em gotas se desfez, repetiu-se o teste com a solução seguinte de menor tensão. O procedimento foi executado utilizando-se uma haste de algodão limpo a fim de evitar a contaminação das soluções.

$\mathrm{O}$ teste de ângulo de contato baseou-se na observação do ângulo formado entre o plano adjacente à gota de água e a superfície da membrana. Após determinar visualmente o ângulo formado, classificou-se a superfície das membranas, de acordo com Yuan \& Lee (2013).

\subsubsection{Seletividade - Grau de retenção de proteínas globulares}

O grau de retenção é a medida da capacidade da membrana em reter moléculas. Sua determinação foi realizada, a partir da utilização de duas moléculas proteicas indicadoras, segundo Baker (2012): Albumina de Soro Bovino - BSA (massa molecular de 67.000 g.mol ${ }^{-1}$ ) e Y-Globulina 
Bovino (com massa molecular de 150.000 g. mol ${ }^{-1}$ ). Dessa forma, o grau de retenção é calculado pela Equação (1), conforme Poletto et al. (2012).

$$
G R(\%)=\left[1-\left(\frac{C_{p}}{C_{c}}\right)\right] \times 100
$$

Sendo $G R(\%)$ o grau de retenção de proteína; $C_{p}$ a concentração da proteína em questão no permeado e $C_{c}$ a concentração da proteína na alimentação. Para a determinação da concentração exata das proteínas na alimentação e nos permeados obtidos, curvas padrões de cada proteína foram preparadas (Absorbância x Concentração), por meio dos resultados obtidos da leitura realizada pelo espectrofotômetro UV/VIS/NIR - JASCO - V 570. Assim, a leitura espectrofotométrica foi feita, utilizando-se o Método Direto de Análise, segundo MED (2013), a 280 nm (em triplicata).

\subsubsection{Raio médio dos poros}

Determinou-se o tamanho estimado dos poros das membranas, a partir do grau de retenção das proteínas globulares de raio conhecido obtido na Equação (1). Assim, utilizando-se a Equação 2 (FERRY, 1936) estimou-se o radio médio dos poros das membranas.

$$
G R(\%)=\left[1-2 \times\left(1-\frac{a}{r}\right)^{2}+\left(1-\frac{a}{r}\right)^{4}\right]
$$

Sendo $G R(\%)$ o grau de retenção da proteína; $a$ o raio da proteína; $r$ o raio médio estimado dos poros da membrana. Segundo Baker (2012), o diâmetro nominal, $a$, de BSA é de 3,2 nm e da YGlobulina é de 4,2 nm. Assim, o raio médio dos poros de cada membrana foi obtido pela média dos resultados de raio encontrados.

\subsubsection{Espessura das membranas}

As espessuras das membranas foram determinadas usando-se o equipamento Elcometer 345. Esse equipamento consiste basicamente de uma chapa metálica em que as amostras foram sobrepostas para serem mensuradas diretamente por um sensor, cujo resultado de espessura é apresentado em um visor do equipamento.

\subsubsection{Determinação do fluxo de permeado}

A Figura 2 apresenta o esquema de um sistema para a determinação do fluxo de permeado. Nesse sistema o registro de dados é realizado automaticamente a uma pressão de 0,05 Mpa. Essa pressão é mantida pelo $\mathrm{O}_{2}$ liberado de um tanque pressurizado e monitorada por um manômetro digital (2). Esse tanque têm uma válvula na saída (1) e uma válvula de alívio (3) que possibilitaram a permanência constante da pressão. A permeabilidade através das membranas sintetizadas foi testada, 
utilizando-se água obtida pelo processo de osmose inversa, soluções de $100 \mathrm{mg} . \mathrm{L}^{-1}$ de BSA e de $\Upsilon$ Globulina. Assim, para cada teste, as membranas (6) foram acondicionadas em um módulo de filtração perpendicular (4) sob rotação de $400 \mathrm{rpm}$, fornecida pelo agitador magnético AS ONE de modelo REXIM RS - 1DN (5). A massa das amostras de permeado (7) foi determinada pela balança analítica AND de modelo FZ - 2000i (8) e registrados precisamente e automaticamente, a cada 30 segundos, em um computador HP Pavilion dv6 (9). A área filtrante de cada membrana usada nessa avaliação foi de $11,1 \times 10^{-4} \mathrm{~m}^{2}$. Após a conversão dos fluxos em $\quad \mathrm{kg} \cdot \mathrm{h}^{-1} \cdot \mathrm{m}^{-2}$, obteve-se graficamente $\left(\mathrm{kg} \cdot \mathrm{m}^{-2} \mathrm{x}\right.$ Tempo) os fluxos estáveis.

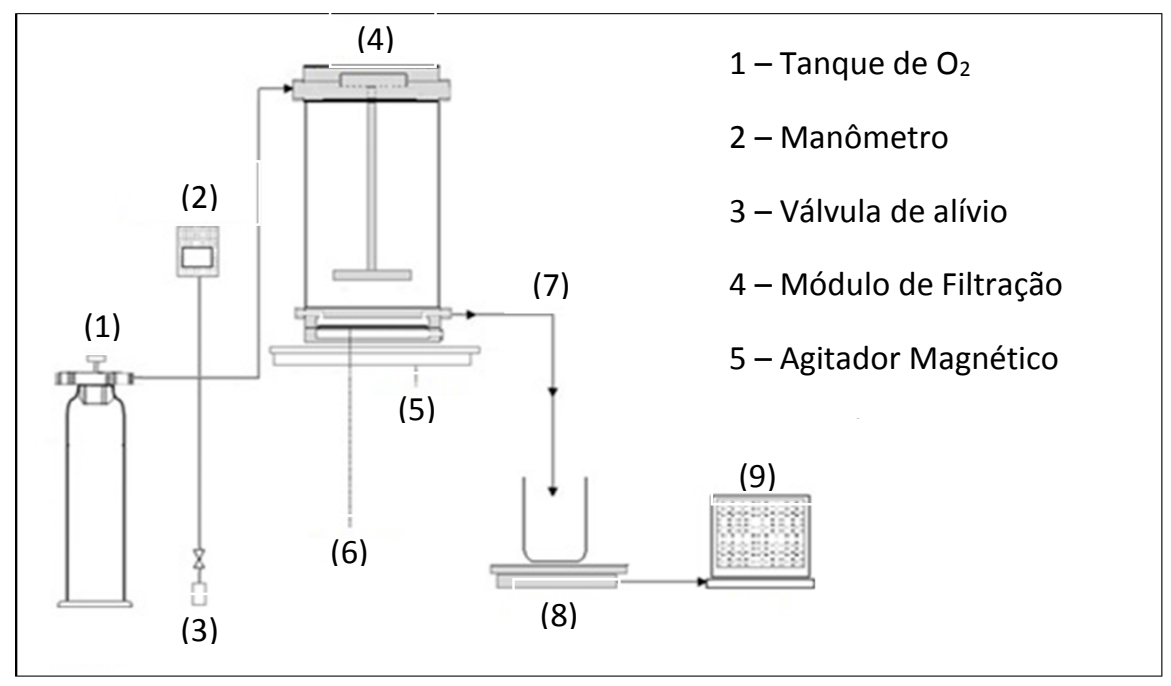

Figura 2. Sistema automatizado utilizado na avaliação de fluxo de permeado

Os fluxos estáveis considerados de cada membrana, apresentados neste trabalho, foram obtidos a partir do coeficiente angular de um modelo de regressão linear simples, adotado quando a variabilidade dos dados explicada pelo respectivo modelo foi superior a 99\%, ou seja, com um coeficiente de determinação, $\mathrm{R}^{2}$, de 0,99 .

Assim, os ensaios da avaliação dos fluxos com água de osmose inversa tiveram a duração de 1 hora, porém o valor dos fluxos considerados estáveis compreendeu dados de um intervalo mínimo de 30 minutos $\left(\mathrm{R}^{2}=0,99\right)$. Por essa razão, foi necessário desprezar valores de dados iniciais de, praticamente, cada série. De forma semelhante, os ensaios da avaliação com as soluções de BSA e de Y-Globulina tiveram duração de 2 horas, porém o valor dos fluxos compreendeu dados de um intervalo mínimo de 1 hora $\left(\mathrm{R}^{2}=0,99\right)$.

\section{Resultados e discussão}

\subsection{Síntese das membranas}

O sistema automático montado controlou e registrou a temperatura da água que manteve as soluções na temperatura desejada, as quais foram homogeneizadas completamente (Figura 3). 


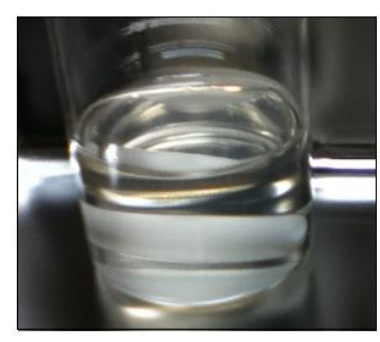

Figura 3. Solução Polimérica homogeneizada

\subsection{Caracterização das membranas produzidas}

\subsubsection{Teste de tensão de molhabilidade e Ângulo de contato}

Os resultados das avaliações do teste de tensão de molhabilidade e de ângulo de contato da água de osmose inversa formado com a superfície de cada membrana sintetizada, segundo Elzbieciak et al. (2008) e Yuan \& Lee (2013), respectivamente são apresentados na Tabela 1.

Tabela 1 - Tensão de molhabilidade e Ângulo de contato das Membranas

\begin{tabular}{|c|c|c|c|}
\hline Membrana & $\begin{array}{c}\text { Wetting } \\
\text { Tension Test } \\
\text { Mixture }\end{array}$ & $\begin{array}{c}\text { Ângulo de } \\
\text { contato }\end{array}$ & $\begin{array}{c}\text { Classificação } \\
\text { da superfície }\end{array}$ \\
\hline M1 & $>73,0 \mathrm{mN} / \mathrm{m}$ & $<90^{\circ}$ & Hidrofílica \\
\hline M2 & $>73,0 \mathrm{mN} / \mathrm{m}$ & $<90^{\circ}$ & Hidrofílica \\
\hline M3 & $>73,0 \mathrm{mN} / \mathrm{m}$ & $<90^{\circ}$ & Hidrofílica \\
\hline M4 & $>73,0 \mathrm{mN} / \mathrm{m}$ & $<90^{\circ}$ & Hidrofílica \\
\hline
\end{tabular}

O polímero PVDF é hidrofóbico (CALLISTER, 1991) e possui um ângulo de contato da água próximo de $91^{\circ}$ (HUANG et al., 2010). O polímero PMMA é hidrofílico e possui um ângulo de contato de aproximadamente $68^{\circ}$ (MA et al., 2007). No estudo de Petrus et al. (1998), foi detectado que, com o aumento na concentração de PMMA nas membranas de PVDF, houve um acréscimo importante nos fluxos permeados. Com base no ângulo de contato do PVDF (próximo de $90^{\circ}$ ) e do PMMA (inferior a $90^{\circ}$ ), é possível verificar que o polímero PMMA, provavelmente, proporcionou o aumento da hidrofilicidade na superfície das membranas produzidas nesse trabalho. Sendo assim, verificou-se que o ângulo formado entre o plano adjacente à gota de água e a superfície de cada membrana foi inferior a $90^{\circ}$ e segundo Yuan \& Lee (2013), as mesmas podem ser classificadas como hidrofílicas. Assim, por meio da Tabela 1, é possível verificar que todas as membranas sintetizadas 
tiveram o mesmo resultado de tensão superficial (aproximadamente de 73,0 mN/m) e de ângulo de contato $\left(\leq 90^{\circ}\right)$.

Associando-se os parâmetros ângulo de contato com os da tensão de molhabilidade, segundo Adamson \& Gast (1997), materiais hidrofílicos têm valores de tensão de superfície elevadas, ratificando-se o resultado experimental acima apresentado, de ambos os parâmetros das membranas produzidas neste estudo.

\subsubsection{Seletividade - Grau de retenção de proteínas globulares}

A Figura 3 apresenta a curva padrão de BSA (coeficiente de determinação, $R^{2}=0,98$ ) e a Figura 4, de $\Upsilon$-Globulina (coeficiente de determinação, $R^{2}=0,99$ ) obtidas.

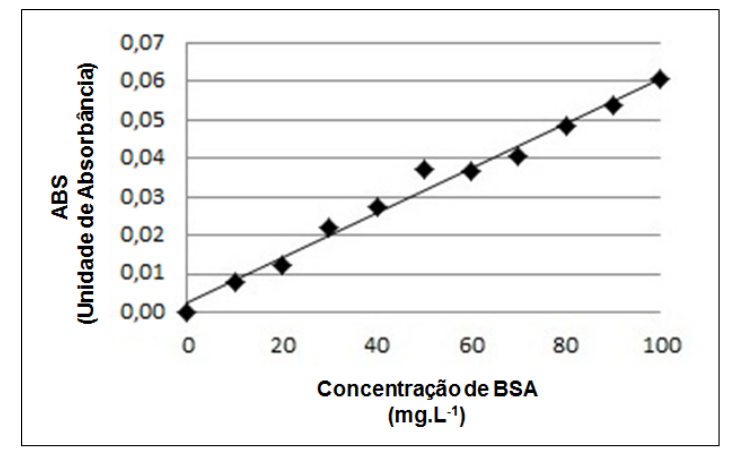

Figura 3. Curva Padrão de BSA

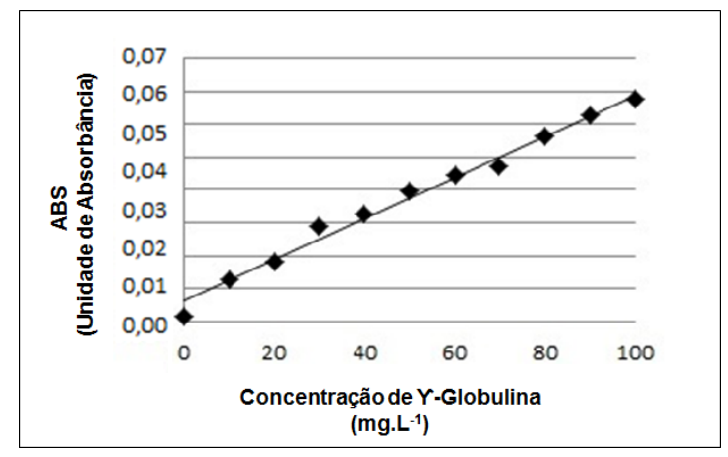

Figura 4. Curva Padrão de $\Upsilon$-Globulina

A Tabela 2 apresenta o grau de retenção das proteínas globulares BSA e Y-Globulina das membranas sintetizadas, o qual foi determinado utilizando-se a Equação 1.

Tabela 2 - R(\%) de Proteínas Globulares das Membranas 


\begin{tabular}{|l|c|c|}
\hline \multirow{2}{*}{ Membrana } & \multicolumn{2}{|c|}{ Grau de Retenção, R(\%) } \\
\cline { 2 - 3 } & BSA & Y-Globulina \\
\hline $\mathrm{M}_{(8 \% \mathrm{PVDF}+1 \% \mathrm{PMMA}+1 \% \mathrm{KCl})}$ & 5,6 & 22,4 \\
\hline $\mathrm{M} 2_{(8 \% \mathrm{PVDF}+1 \% \mathrm{PMMA}+1 \% \mathrm{LiCl})}$ & 23,7 & 62,7 \\
\hline $\mathrm{M} 3_{(10 \% \mathrm{PVDF}+1 \% \mathrm{PMMA}+1 \% \mathrm{KCl})}$ & 25,5 & 49,6 \\
\hline $\mathrm{M} 4{ }_{(10 \% \mathrm{PVDF}+1 \% \mathrm{PMMA}+1 \% \mathrm{LiCl})}$ & 34,6 & 80,5 \\
\hline
\end{tabular}

Por meio da Tabela 2, é possível observar que com o aumento da concentração polimérica do polímero principal (PVDF), p/p, com o aditivo $\mathrm{KCl}$ (M1 e M3) ou LiCl (M2 e M4), houve uma tendência de se obter maiores retenções de ambas as proteínas globulares. A provável justificativa para essa ocorrência é a formação de poros menores com o aumento da concentração polimérica, como será apresentado mais adiante.

Em relação à diferença do grau de retenção entre as proteínas globulares (BSA e $\Upsilon$ Globulina) de uma mesma membrana, é possivelmente explicada pela diferença de tamanho dessas proteínas. Segundo Baker (2012), o diâmetro molecular nominal da proteína BSA (6,4 nm) é menor do que o da proteína Y-Globulina $(8,4 \mathrm{~nm})$, consequentemente, o grau de retenção de BSA tende a ser menor do que o da proteina globular Y-Globulina, como foi detectado. Assim, para o mesmo autor, se os poros estão na ordem do tamanho molecular de, pelo menos, alguns dos componentes na mistura de alimentação, a difusão dos mesmos irá ser restringida ou impedida.

As membranas de mesma concentração polimérica, produzidas com o sal LiCl (M2 e M4), apresentaram um maior $\mathrm{R}(\%)$ de ambas as proteínas globulares do que as produzidas com o sal $\mathrm{KCl}$ (M1 e M3). Esse resultado, provavelmente pode ser explicado pela tendência do LiCl aumentar a porosidade das membranas, cujo resultado maior de retenção de soluto, foi também demonstrado por Idris \& Ahmed (2012).

\subsubsection{Raio médio dos poros e Espessura das membranas}

Por meio da Equação 2, determinou-se a média da estimativa do raio dos poros das membranas, a partir do grau de retenção de cada proteína globular (BSA e Y-Globulina). Portanto, a Tabela 3 apresenta o raio médio de poros das membranas sintetizadas, bem como das respectivas espessuras mensuradas.

Tabela 3 - Raio médio dos poros e espessura das membranas 


\begin{tabular}{|c|c|c|}
\hline Membrana & $\begin{array}{c}\text { Raio Médio dos } \\
\text { Poros (nm) }\end{array}$ & Espessura ( $\boldsymbol{\mu m})$ \\
\hline $\begin{array}{c}\text { M1 } \\
(8 \% \mathrm{PVDF}+1 \% \mathrm{PMMA}+1 \% \mathrm{KCl})\end{array}$ & 5,5 & 108,4 \\
\hline $\begin{array}{c}\mathrm{M} 2 \\
(8 \% \mathrm{PVDF}+1 \% \mathrm{PMMA}+1 \% \mathrm{LiCl})\end{array}$ & 4,5 & 140,8 \\
\hline $\begin{array}{c}\mathrm{M} 3 \\
(10 \% \mathrm{PVDF}+1 \% \mathrm{PMM}+1 \% \mathrm{KCl})\end{array}$ & 4,6 & 191,9 \\
\hline $\begin{array}{c}\mathrm{M} 4 \\
(10 \% \mathrm{PVDF}+1 \% \mathrm{PMMA}+1 \% \mathrm{LiCl})\end{array}$ & 3,9 & 203,3 \\
\hline
\end{tabular}

Conforme a Tabela 3, é possível verificar evidentemente que o raio médio dos poros das membranas produzidas com o mesmo sal, diminuiu com o aumento da concentração do polímero PVDF. Porém, a espessura das membranas tornou-se maior com o aumento da concentração do mesmo polímero, como foi também observado por Xiao et al. (2009). No entanto, observou-se uma espessura maior nas membranas produzidas com o sal $\mathrm{LiCl}$, de mesma concentração polimérica.

À medida que se aumentou a concentração polimérica das membranas, segundo o estudo de Franco et al. (2010), menores foram os raios médios de poros formados nas mesmas. Segundo Petrus et al. (1998), aumentando-se a concentração polimérica diminui-se os macrovazios de uma membrana por promover o estiramento dos canais porosos e o aumento da porosidade, contribuindo assim, para a formação de diâmetros menores de poros. Isso justifica a fomação de menores poros, à medida que se aumentou a concentração de PVDF utilizando-se o mesmo sal. Outra justificativa para a formação de menores poros é o aumento da viscosidade à medida que se aumentou a concentração de PVDF devido, à menor distância entre as cadeias do polímero (Lu \& Li, 2009). Dessa forma, com o aumento da viscosidade, a difusão do solvente e não solvente na matriz polimérica é menor, formando-se assim, pequenas cavidades na subestrutura.

No estudo de Susuki et al. (2012) e Ribeiro et al. (2007), membranas sintetizadas com os mesmos polímeros PVDF e PMMA, as quais apresentaram 8\% PVDF e 12 a 17\% PVDF, respectivamente, apresentaram uma estimativa de poros maiores. Dessa forma, ao comparar a membrana de Susuki et al. (2012) e as de Ribeiro et al. (2007) com as sintetizadas nesse estudo, é possível verificar que as últimas possuíram menor raio, com economia de material polimérico.

Importantes efeitos sobre a formação das características morfológicas e propriedades funcionais da membrana sintetizada podem ser influenciados pelas condições adotadas na técnica de precipitação por imersão (KHAYET \& MATSUURA, 2011; FIGUEREDO et al., 2009), devido à influência de vários parâmetros termodinâmicos e cinéticos envolvidos (FIGUEREDO et al., 2009). Assim, a provável justificativa para a obtenção de menores raios médios, tanto na membrana com a equivalente concentração polimérica quanto aquelas com maior concentração de PVDF, deve-se ao fato das pequenas variações adotadas nas condições físicas ou operacionais do procedimento utilizado no presente estudo em relação ao realizado por Susuki et al. (2012) e Ribeiro et al. (2007).

\subsubsection{Determinação do fluxo de permeado}


Os dados coletados referentes aos fluxos estáveis de permeados das membranas (M1, M2, M3 e M4) produzidas, representados graficamente, são apresentados na forma de regressão linear com coeficiente de correlação de 0,99. Dessa forma, a Figura 4 apresenta os dados coletados da avaliação com água de osmose inversa, as Figuras 5 e 6, da avaliação com a solução de $100 \mathrm{mg} / \mathrm{L}$ BSA e $\Upsilon$-Globulina, respectivamente.

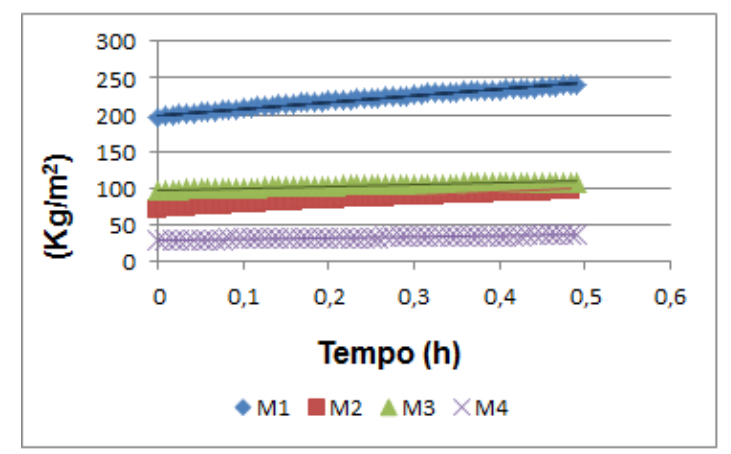

Figura 4. Fluxo estável de permeado de água de osmose inversa

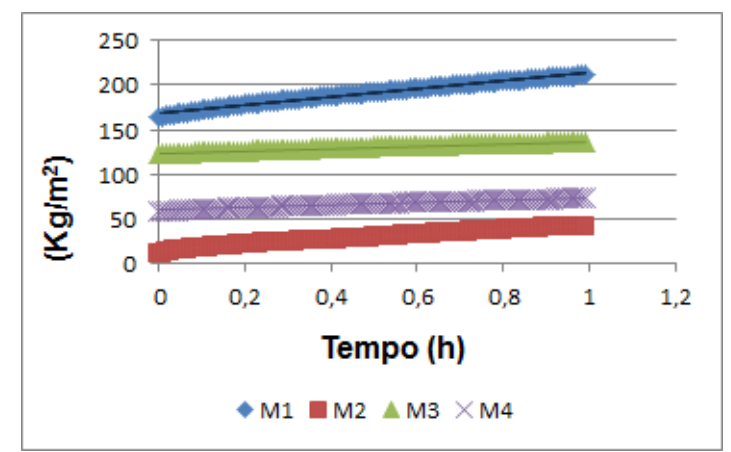

Figura 5. Fluxo estável de permeado na avaliação com solução de BSA

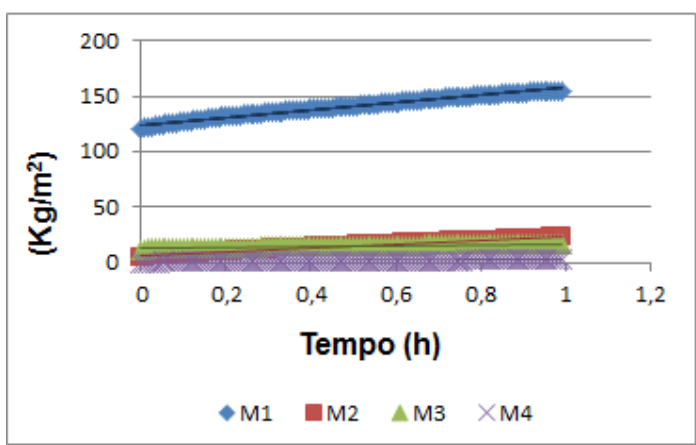

Figura 6. Fluxo estável de permeado na avaliação com solução de Y-Globulina

Por meio das Figuras 4, 5 e 6 é possível verificar que as membranas de mesma concentração e elaboradas com o sal $\mathrm{LiCl}$ (M2 e M4) atingiram a estabilidade mais rapidamente do que as elaboradas com o $\mathrm{KCl}$ (M1 e M3). Além disso, essas últimas membranas apresentaram menor fluxo de permeado em todas as avaliações realizadas, como pode ser verificado na Tabela 4, exceto o fluxo da membrana M4 avaliada com a solução de BSA, o qual apresentou maior do que o da M3.

Tabela 4. Fluxos estáveis de permeado das membranas produzidas 


\begin{tabular}{|c|c|c|c|}
\hline \multirow{2}{*}{ Membrana } & \multicolumn{3}{|c|}{ Fluxos Estáveis } \\
\cline { 2 - 4 } & $\begin{array}{c}\text { Água de osmose } \\
\text { inversa } \\
\left(\mathbf{k g . h}^{-1} \cdot \mathbf{m}^{-2}\right)\end{array}$ & $\begin{array}{c}\text { Solução de BSA } \\
\left(\mathbf{k g . h}^{-\mathbf{1}} \cdot \mathbf{m}^{-2}\right)\end{array}$ & $\begin{array}{c}\text { Solução de } \\
\text { Y-Globulina } \\
\left(\mathbf{k g . h}^{-\mathbf{1}} \cdot \mathbf{m}^{-2}\right)\end{array}$ \\
\hline $\begin{array}{c}\mathrm{M} 1 \\
(8 \% \mathrm{PVDF}+1 \% \mathrm{PMMA}+1 \% \mathrm{KCl})\end{array}$ & 86,5 & 45,4 & 32,6 \\
\hline $\begin{array}{c}\mathrm{M} 2 \\
(8 \% \mathrm{PVDF}+1 \% \mathrm{PMMA}+1 \% \mathrm{LiCl})\end{array}$ & 47,6 & 28,4 & 17,1 \\
\hline $\begin{array}{c}\mathrm{M} 3 \\
(10 \% \mathrm{PVDF}+1 \% \mathrm{PMM}+1 \% \mathrm{KCl})\end{array}$ & 25,7 & 13,4 & 4,6 \\
\hline $\begin{array}{c}\mathrm{M} 4 \\
(10 \% \mathrm{PVDF}+1 \% \mathrm{PMMA}+1 \% \mathrm{LiCl})\end{array}$ & 15,2 & 14,7 & 2,2 \\
\hline
\end{tabular}

A produção de membranas porosas utilizando-se a técnica de inversão de fases por imersão-coagulação, quaisquer pequenas variações nas condições operacionais no preparo de uma membrana podem acarretar variações significativas na sua estrutura e, consequentemente, no seu desempenho (HABERT et al., 2006). Assim, o resultado da M4 possivelmente, pode ser justificado pela presença de defeito (grandes poros) na amostra avaliada com a solução de BSA da respectiva membrana. Isso mostra que é um dos desafios dos pesquisadores, produzir membranas com morfologia sem defeitos.

Contudo, observando-se a Tabela 4, pode-se afirmar de forma generalizada, que os fluxos de permeado com água de osmose inversa e com as soluções de $100 \mathrm{mg} / \mathrm{L}$ BSA e de $\Upsilon$-Globulina, foram menores nas membranas de maior concentração de PVDF e sintetizadas com o sal LiCl.

\section{Conclusões}

Verificou-se que o sistema automatizado utilizado neste trabalho facilitou a operação de obtenção de membranas poliméricas.

Os parâmetros tensão de molhabilidade e ângulo de contato mostraram o aumento da hidrofilicidade nas membranas produzidas com PMMA.

O tamanho dos poros das membranas foi menor, nas membranas com maior concentração polimérica e produzidas com $\mathrm{LiCl}$, porém apresentaram maior espessura. Além disso, essas membranas apresentaram um grau de retenção maior de proteínas globulares.

Por fim, as membranas obtidas com o procedimento adotado mostraram ser mais seletivas do que às membranas produzidas semelhantemente encontradas na literatura. 


\section{Agradecimentos}

Agradeço às agências de fomento Capes, CNPq, FINEP e Fundação Araucária, pelo apoio financeiro.

\section{Bibliografia}

ADAMSON, A. W. \& GAST, A. P. 1997. Physical Chemistry of Surfaces. A WileyInterscience Publication. 6. ed. New York: John Wiley \& Sons.

BAKER, R. W. 2012. Membrane Technology and Applications. 3. ed. California: John Wiley \& Sons.

BALANNEC, B., VOURCH, M., RABILLER-BAUDRY, M. \& CHAUFER, B. Comparative study of different nanofiltration and reverse osmosis membranes for dairy effluent treatment by dead-end filtration. 2005. Separation and Purification Technology, 42, 195-200.

BALDASSO, C., BARROS, T.C. \& TESSARO, I. C. Concentration and purification of whey proteins by ultrafiltration. 2011. Desalination, Amsterdam, 278, 381-386.

BASTOS, A.C.L.M., RODRIGUES, E.M.S. \& SOUZA, J.P.L. de. 2011. Físico-Química. 22. ed. Belém: Universidade Federal do Pará, 302.

BRANZINHA, C. \& CRESPO, J. G. 2010. Membrane processing: Natural antioxidants from winemaking by-products. Elsevier - Filtration \& Separation, 47, 2, 32-35.

CALLISTER, W. D. 1991. Materials Science and Engineering: An Introduction. John Wiley \& Sons,Inc., New York, NY.

CARVALHO, R. B., BORGES, C. P. \& NÓBREGA, R. 2001. Formação de Membranas Planas Celulósicas por Espalhamento Duplo para os Processos de Nanofiltração e Osmose Inversa.

Polímeros: Ciência e Tecnologia, 11, 2, 65-75, 2001.

ELZBIECIAK, M., KOLASINSKA, M. \& WARSZYNSKI, P. 2008. Characteristic of

Polyelectrolyte Multilayers: the Effect of Polyion Charge on Thickness and Wetting Properties.

Colloids Surf. A, 321, 258-261.

FERRY, J. D. 1936. Ultrafilter membranes and ultrafiltration. Che. Rev., 18, 373, 373-455.

FIGUEREDO, A. K. M., PEREIRA, C. C. \& BORGES, C. P. 2009. Desenvolvimento de Membranas com Maior Resistência Mecânica para Aplicação em Biorreatores. CONGRESSO BRASILEIRO DE ENGENHARIA QUÍMICA EM INICIAÇÃO CIENTÍFICA - Uberlância - MG. FRANCO, P. Q., SILVA, J.C. \& BORGES, J.P. 2010. Produção de fibras de hidroxiapatite por electrofiação. C.Tecn. Mat., 22, 1-2, 57-64, Lisboa.

HABERT, A. C., BORGES, C. P. \& NOBREGA, R. 2006. Processo de Separação por Membranas. Escola Piloto em Engenharia Química COPPE/UFRJ. Rio de Janeiro: e-papers. HUANG, F. L., WANG, Q. Q., WEI, Q. F., GAO, W. D., SHOU, H. Y. \& JIANG, S. D. 2010. Dynamic wettability and contact angles of poly(vinylidene fluoride) nanofiber membranes grafted with acrylic acid. eXPRESS Polymer Letters, 4, 9, 551558

IDRIS, A. \& AHMED, I. 2007. A Production of olyethersulfone Asymmetric Membranes Using Mixture of Two Solvents and Lithium Chloride as Additive. Jurnal Teknologi, 47, 25-34.

KOCHERGINSKY, N.M., YANG, Q. \& SEELAM, L. 2007. Recent advances in supported liquid membrane technology. ScienceDirect, 53, 171-177.

ISO 8296. 2003. Plastics - Film and sheeting - Determination of Wetting Tension [Online], 3. Disponível: http://www.iso.org/iso/catalogue_detail.htm?csnumber=38451 [Acessado em 26 Janeiro de 2013]

KHAYET, M. \& MATSUURA, T. 2011. Membrane Distillation: Principles and Applications. The Netherlands: Elsevier.

KOCHERGINSKY, N.M., YANG, Q. \& SEELAM, L. 2007. Recent advances in supported liquid membrane technology. ScienceDirect, 53, 171-177. 
LEITE, A. M. D., ARAÚJO, E. M., LIRA, H. de L., BARBOSA, R. \& ITO, E. N. 2009.

Obtenção de Membranas Microporosas a partir de Nanocompósitos de Poliamida 6/Argila

Nacional. Parte 1: Influência da Presença da Argila na Morfologia das Membranas. Polímeros:

Ciência e Tecnologia, 19, 4, 271-277.

LOEB, S. \& SOURIRAJAM, S. 1962. Sea water desmineralization by means of an osmotic membrane, Adv. Chem. Ser., 28, 117.

LU, X. \& LI, X. 2009. Preparation of Polyvinylidene Fluoride Membrane Via a Thermally Induced Phase Separation Using a Mixed Diluent. Journal of Applied Polymer Science, 114, 1213-1219.

MA, Y., CAO, X., FENG, X., MA, Y. \& ZOU, H. 2007. Fabrication of super-hydrophobic film from PMMA with intrinsic water contact angle below $90^{\circ}$. Polymer, 48, 7455-7460.

MED. The Measurent Principle of the low and the actual protein qualification using a Spectrophotometer [Online]. Disponível: http://www.med.gifu-

u.ac.jp/cell_signal/page_610.html [Acessado em 6 fevereiro de 2013]

PETRUS, J. C. C., MENEZES, H. C. \& PIRES, A. T. N. 1998. Preparação e Caracterização de Membranas Microporosas obtidas a partir de blendas de PVDF/PMMA. Polímeros: Ciência e Tecnologia, 8, 1, 67-74.

POLETTO, P., DUARTE, J., LUNKES, M. S., SANTOS, V. dos \& ZENI, Mára. 2012.

Avaliação das Características de Transporte em Membranas de Poliamida 66 Preparadas com Diferentes Solventes. Polímeros, v. 22, n. 3, p. 273-277.

RAHIMPOUR, A., MADAENI, S. S., AMIRINEJAD, M., MANSOURPANAH, Y. \& ZERESHKI, S. 2009. The effect of heat treatment of PES and PVDF ultrafiltration membranes on morphology and performance for milk filtration, Journal of Membrane Science, 330, 1-2, 189-204.

RIBEIRO, R. M., BERGAMASCO, R. \& GIMENES, M. L. 2002. Membranes synthesis study for colour removal of a textile effluent. Desalination, 145, 61-63. RIBEIRO, R. M., BERGAMASCO, R., GIMENES, M. L. \& DIAS FILHO, B. P. 2004. Potabilização de águas portadoras da bactéria Escherichia coli por meio de membranas poliméricas. Acta Scientiarum. Technology, 26, 2, 85-90.

RIBEIRO, R. M., BERGAMASCO, R., GIMENES, M. L. \& MÜLLER, C. M. O. 2007. Preparacíon de Membranas para produção de água potable. Información Tecnológica, 18, 15-21. SUSUKI, F. F. M., BERGAMASCO, R., TAVARES, C. R. G. \& BALDASSO, T. 2012. Production and application of porous membrane for removal of contaminants in treated water. Acta Scientiarum: Technology, 34, 4, 421-425.

YOUNG, T. H., HUANG, J. H. \& CHUANG, W. Y. 2002. Effect of evaporation temperature on the formation of particulate membranes from crystalline polymers by dry-cast process. European Polymer Journal, 38, 1, 63-72.

YUAN, Y. \& LEE, T. R. 2013. Surface Science Techniques. Springer Series in Surface Sciences 51, DOI 10.1007/978-3-642-34243-1_1. Springer-Verlag Berlin Heidelberg.

XIAO, Q., WANG, X., LI, W., LI, Z., ZHANG, T. \& ZHANG, H. 2009. Macroporous polymer electrolytes based on PVDF/PEO- $b$-PMMA block popolymer blends for rechargeable lithium ion battery. J. Membr. Sci., 334, 1-2, 117-12. 